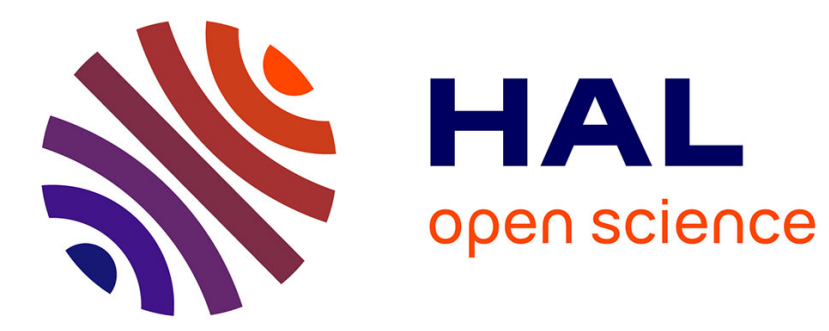

\title{
Socializing on MOOCs: comparing university and self-enrolled students
}

François Bouchet, Rémi Bachelet

\section{To cite this version:}

François Bouchet, Rémi Bachelet. Socializing on MOOCs: comparing university and self-enrolled students. 6th European MOOCs Stakeholders Summit (EMOOCs 2019), May 2019, Naples, Italy. pp.31-36, 10.1007/978-3-030-19875-6_4 . hal-02101559

\section{HAL Id: hal-02101559 \\ https://hal.science/hal-02101559}

Submitted on 24 May 2019

HAL is a multi-disciplinary open access archive for the deposit and dissemination of scientific research documents, whether they are published or not. The documents may come from teaching and research institutions in France or abroad, or from public or private research centers.
L'archive ouverte pluridisciplinaire HAL, est destinée au dépôt et à la diffusion de documents scientifiques de niveau recherche, publiés ou non, émanant des établissements d'enseignement et de recherche français ou étrangers, des laboratoires publics ou privés. 


\title{
Socializing on MOOCs: comparing university and self-enrolled students
}

\author{
François Bouchet ${ }^{1[0000-0001-9436-1250]}$ and Rémi Bachelet ${ }^{2[0000-0001-8725-0384]}$ \\ ${ }^{1}$ Sorbonne Université, CNRS, Laboratoire d'Informatique de Paris 6, LIP6, 75005 Paris, France \\ ${ }^{2}$ Centrale Lille, PRES Université Lille Nord de France, F-59650 Villeneuve d’Ascq, France \\ francois.bouchet@lip6.fr \\ remi.bachelet@centralelille.fr
}

\begin{abstract}
MOOCs are becoming more and more integrated in the higher education landscape of learning, with many institutions now pushing their students towards MOOC as part of their curriculum. But what does it mean for other MOOC learners? Are these students socializing the same way when they have an easier possibility to interact with classmates offline? Is the fact that they do not personally choose to enroll in a MOOC also having an effect? In this paper, we compare university-enrolled students to other MOOC participants and in particular other self-enrolled students, to examine how and why they socialize on and around the MOOC. Using data from two French MOOCs in project management, we show that university-enrolled students are less attracted by forums and seem to interact less than others when the workload increases, which could lead to misleading conclusions when analyzing data. We therefore encourage MOOC researchers to be particularly mindful of this new trend when performing social network analyses.
\end{abstract}

Keywords: MOOC, Social Interaction, Interaction Motivation, Students, Enrollment.

\section{Introduction}

MOOCs have started as an alternative to traditional education and have met a notable success in lifelong learning. However, universities and higher education institutions - which were the original target for MOOC education - are now catching up and implementing MOOCs in their curriculum, with professors either suggesting or requiring that their students register and complete a MOOC as part of their class.

This growing use of MOOCs in universities raises a question: does this new public behave in a specific way when compared to self-enrolled students? Self-determination theory [1] highlights how the nature of the motivation (extrinsic vs. intrinsic) plays a critical role in learning outcomes. Thus, whether a MOOC student is self-enrolled or compelled to enroll might play a critical role in their learning behavior. Only one study so far has compared MOOC vs. for-credit courses but it did not consider the fact MOOCs could be included in for-credit courses [2]. Of course, one would expect a much lower dropout rate (i.e. no "funnel of participation" [3]) when registration is compulsory, but what about other behaviors? 
Another key aspect is that university-enrolled students have an easy offline access to other people following the MOOC, and therefore may not need as much to go towards forums or dedicated pages on social networks. It is well-known that socialization is key to learning [4], with isolation being often mentioned as one of the major factors for dropping out [5]. Thus, one can wonder how this might affect the reliability of some observations in the data collected. Indeed, detecting the loss of social relationships has been shown to be an important way to detect early drop-out in MOOCs [6], and several tools have been developed to help with this issue [7, 8]. One could also wonder the impact this population might have for social network analyses, a common method [9], particularly when dealing with MOOC data [10].

In this study, we compare online social behaviors like the use of discussion forums, social networks, and other means of interacting with peer learners. More precisely, we chose to investigate the following research questions:

(RQ1) Are students enrolled by their university socializing differently from other MOOC participants in general?

(RQ2) Are students enrolled by their university socializing differently from other MOOC university students in particular?

Our hypotheses are that students enrolled by university must be doing most of the socialization outside of the platform, with their classmates, and therefore should be less interested in socializing with other MOOC participants. They should therefore differ from both MOOC participants, and other (self-enrolled) students in particular.

\section{Methods}

\subsection{Datasets and subsamples}

We consider two datasets corresponding to two different sessions of the same French MOOC on project management called GdP. It corresponds to the $6^{\text {th }}$ (2015) and $8^{\text {th }}$ (2016) edition of this popular biannual MOOC, and referred further on as GdP6 and GdP8. This MOOC allows participants to obtain a basic certificate, corresponding to a moderate workload (15-25 hours), as well as an advanced certificate, corresponding to a heavier workload (35-45 hours). For each of the following analyses, we therefore split the datasets in two, depending on the certificate the participants were working on. Moreover, several universities suggest or compel their students to follow this MOOC as part of a larger training course in project management, which allows us to investigate our initial question by considering two separate samples: (1) "university-enrolled students" (UES), for the MOOC participants enrolled by their university, (2) "other MOOC participants" (OMP), for the rest of the participants (enrolled on their own). Students in the latter categories were coming from 3 to 8 different curriculum associated to 6 different universities. Additionally, in GdP8, participants were also asked about their socio-professional status, which allows to split the second sample into two subsamples: (2.1) "self-enrolled MOOC students" (SES), for participants who declared to be students but for whom we knew they had not been enrolled by their university, (2.2) "non-students" (NS), for participants who declared they were not students (i.e. unemployed, retired or already employed persons). Participants who did not reply to this question are not considered here. Figure 1 presents a summary of the different aforementioned subsamples for both datasets with their respective sizes.

To answer RQ1, we compared samples UES and OMP from GdP6. To answer RQ2, we compared samples UES and SES from GdP8. Finally, to nuance our answer to RQ2, we also performed a comparison between samples SES and NS, to identify whether it was students overall who were different from other participants. For each research question, we compared separately participants who chose (or were asked by their university) to obtain the basic certificate from participants who chose/were asked to obtain the advanced track, and therefore performed 6 sets of comparisons. 
GdP6 participants $(\mathrm{N}=6049)$

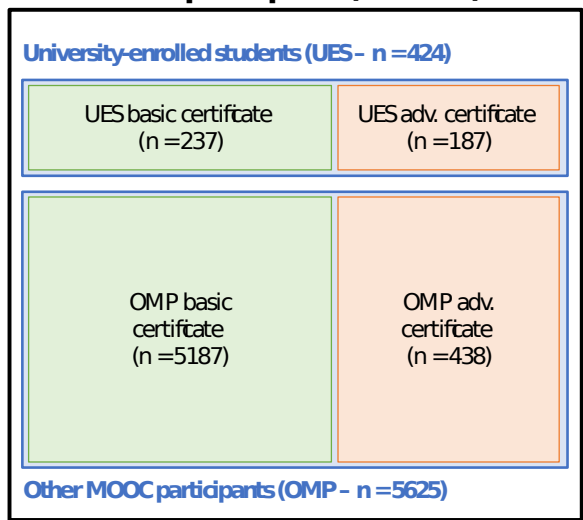

GoP8 partidipants $(\mathrm{N}=5622)$

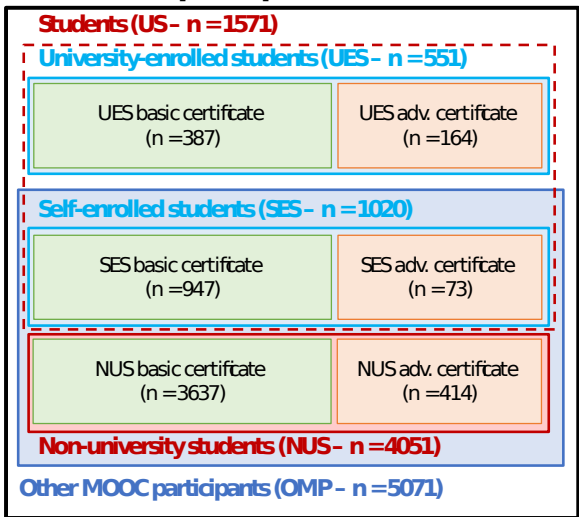

Fig. 1. Summary of the samples used from both datasets (GdP6 and GdP8).

\subsection{Variables considered, data coding and cleaning}

To investigate the need for socialization and the one that really occurred, we relied on 7 different variables extracted from a larger research questionnaire that participants filled at the beginning of week 3 of the MOOC. Although optional, this questionnaire is filled by most of the MOOC students still active at that point (85-95\%). The variables correspond to the answers on a Likert scale to the following statements:

1. ForUseful: "I consider the forums to be useful to me" (from 1 - completely disagree to 5 completely agree)

2. SocNetUseful: “To learn, I consider that social networks (Facebook, Google+, Twitter...) are useful to me" (from 1 - completely disagree to 5 - completely agree)

3. ForUsed: "I have participated to the forums" (from 1 - never, to 3 - regularly)

4. SocNetUsed: "I have exchanged on social networks to ask/answer questions, share experiences..." (from 1 - never, to 3 - regularly)

5. TalkUnclear: "I talk with other students regarding points of the course that seem unclear" (from 1 - completely disagree to 7 - completely agree)

6. TalkCheck: "I interact with other students to see if we have understood the same thing" (from 1 - completely disagree to 7 - completely agree)

7. TalkHowTo: "I interact with other students to know how to work in online courses" (from 1 - completely disagree to 7 - completely agree)

The first 4 variables allow to examine students' interest in the socialization tool on the MOOC, whereas the 3 following ones allow us to see what motivates students to interact with others. Variables 5 to 7 are only available for GdP8 and use a different 7-point scale as they are part of a larger questionnaire. For items 3 and 4, it did not seem relevant to consider more than 3 values considering the activity on forums.

This questionnaire includes several attention checks / trap questions (e.g. "please leave the answer to this question blank"): participants who failed at any of these were excluded from the dataset. Moreover, a few participants did not answer to all questions so the sample size for each analysis slightly varies.

\section{Results}

For each comparison, we ran a Mann-Whitney U test to compare whether the distribution of the answers for each variable were statistically different. To avoid the risk of type I error with multiple comparisons (e.g. 4 tests for RQ1 with GdP6 basic certificate), we corrected the results of each set of tests using Holm-Šídák method. 
Table 1 provides a synthesis of the results. We do not report in details all the results, but for instance, for the first row of Table 1, when comparing (1) university-enrolled students (UES) to (2) other MOOC participants (OMP) in GdP6 for the basic certificate, a Mann-Whitney test indicated that for ForUseful (1) (med=3, mean=2.81) was inferior to (2) (med=4, mean=3.34), U =62209.0, p $<0.001$; for ForUsed (1) (med=1, mean=1.09) was inferior to (2) (med=1, mean=1.17), $U=$ 76731.5, $\mathrm{p}=0.021$, however this result was not statistically significant after correction for multiple tests ; other tests were not statistically significant when comparing these two samples.

Table1. Results summary of Mann-Whitney U tests

\begin{tabular}{|c|c|c|c|c|c|c|c|c|c|}
\hline GdP & $\begin{array}{l}\text { Certific } \\
\text { ate }\end{array}$ & $\begin{array}{l}\text { Samples } \\
\text { compared }\end{array}$ & $\begin{array}{l}\text { For } \\
\text { Useful }\end{array}$ & $\begin{array}{l}\text { For } \\
\text { Used }\end{array}$ & $\begin{array}{l}\text { SocNet } \\
\text { Useful }\end{array}$ & $\begin{array}{l}\text { SocNet } \\
\text { Used }\end{array}$ & $\begin{array}{l}\text { Talk } \\
\text { Unclear }\end{array}$ & $\begin{array}{l}\text { Talk } \\
\text { Check }\end{array}$ & $\begin{array}{l}\text { Talk } \\
\text { HowTo }\end{array}$ \\
\hline 6 & Bas. & UES / OMP & $<* * *$ & $<*$ & $=$ & $=$ & N/A & N/A & N/A \\
\hline 6 & Adv. & UES / OMP & $<* * *$ & $<* * *$ & $<* * *$ & $<* * *$ & N/A & N/A & N/A \\
\hline 8 & Bas. & UES / SES & $<* * *$ & $<*$ & $=$ & $=$ & $=$ & $=$ & $=$ \\
\hline 8 & Adv. & UES / SES & $<*$ & $=$ & $<*$ & $=$ & $=$ & $=$ & $=$ \\
\hline 8 & Bas. & SES / NS & $=$ & $=$ & $>* * *$ & $>* * *$ & $>* * *$ & $>* * *$ & $>* * *$ \\
\hline 8 & Adv. & SES / NS & $=$ & $=$ & $>*$ & $>*$ & $=$ & $>*$ & $>*$ \\
\hline
\end{tabular}

* $\mathrm{p}<0.05$ before adjustment for multiple tests, ${ }^{* * *} \mathrm{p}<0.05$ after adjustment

$=$ means no stat. sig. difference between the two samples, $<$ (resp. $>$ ) means the first sample had a stat. sig. lower (resp. higher) median/mean than the second sample

\section{Discussion}

To answer to RQ1, students enrolled by their university in the basic track found forums to be less useful to them than the other MOOC participants do, but they declared participating as often as other MOOC participants do, and this difference was not observed for social networks. However, when considering the advanced track, requiring a heavier workload, students enrolled by their university found less value in both forums and social networks, and declared using them less than other MOOC participants. This result is in line with our initial hypothesis, but the basic vs. advanced track comparison brings an additional insight: the heavier the workload, the more university-enrolled students must rely on their real-life connections. Conversely, with a moderate workload, despite their perception that forums are less useful, university-enrolled students seem to interact with others on the MOOC in a similar manner as other MOOC participants do (using both the forums and social networks).

When examining the results relative to RQ2, in the basic track, we observe the same difference between university-enrolled students and other students as we did between them and other MOOC participants (i.e. report that forums are less useful to them). This result confirms the difference comes from the university-enrollment factor and not from being students. However, when comparing the two populations of students on the advanced track, the differences between them disappear.

When comparing self-enrolled students with non-students in terms of forum and social networks use and usefulness, the main difference is that in the basic track, students tend to use more and find social network more useful (which could be a generational difference, as students tend to be younger than others and younger people are heavier users of social networks). This difference however is no longer significant when considering the advanced track: the heavier the workload, the more self-enrolled students socialize like other self-enrolled MOOC participants.

Finally, if we consider the last 3 variables to examine what MOOC participants socialize for, there are no difference between self-enrolled students and other students. However self-enrolled students socialize more with others than non-students, for the 3 reasons considered here (clarifying misunderstandings, checking agreement on learning and making sure they use the platform well), particularly in the basic track. 


\section{Conclusion}

Overall, we found that students enrolled by their university have the same motivation as other selfenrolled students to communicate with others. However, they consistently value less the social tools provided to them such as forums. Also, when the workload increases and requires more interaction with other to succeed (peer grading, group projects), whereas self-enrolled students tend to become more like the self-enrolled non-students in terms of use and perceived usefulness of the socialization tools, self-enrolled students become more different, as they rely more on their external socialization networks (classmates) for those tasks.

Knowing the importance of socialization for successful learning, it is critical for MOOCs pedagogical teams to be mindful of students enrolled by their university. Indeed, ignoring their status when analyzing interactions between MOOC participants may lead to incorrectly assume they are dropping out (socializing less than others when they should do it more). As MOOCs become more and more integrated with the overall learning landscape, this is a pitfall more and more analyses might fall into if participants are not explicitly being asked about it. Finally, it might be worth to specifically encourage university-enrolled students to interact with each other through the forums: indeed, as students in general seem more prone to check their understanding with others (a good behavior, from a self-regulation point of view), losing the activity from this population forums might be detrimental to the rest of the participants.

One of the limits of this work is the reliance on a single MOOC: replication studies on other MOOCs would be necessary to validate those results. Future work will also involve checking students’ performance and actual forum usage from log data.

\section{References}

1. Ryan, R.M., Deci, E.L.: Toward a Social Psychology of Assimilation: Self-Determination Theory in Cognitive. In: Self-regulation and autonomy: Social and developmental dimensions of human conduct. p. 191. Cambridge University Press (2013).

2. Almeda, M.V., Zuech, J., Utz, C., Higgins, G., Reynolds, R., Baker, R.S.: Comparing the Factors That Predict Completion and Grades among For-Credit and Open/MOOC Students in Online Learning. Online Learn. 22, 1-18 (2018).

3. Clow, D.: MOOCs and the Funnel of Participation. In: Proceedings of the Third International Conference on Learning Analytics and Knowledge. pp. 185-189. ACM, New York, NY, USA (2013).

4. Wilcox, P., Winn, S., Fyvie-Gauld, M.: "It Was Nothing to Do with the University, It Was Just the People": The Role of Social Support in the First-Year Experience of Higher Education. Stud. High. Educ. 30, 707-722 (2005).

5. Croft, N., Dalton, A., Grant, M.: Overcoming Isolation in Distance Learning: Building a Learning Community through Time and Space. J. Educ. Built Environ. 5, 27-64 (2010).

6. Yang, D., Wen, M., Rosé, C.P.: Peer Influence on Attrition in Massive Open Online Courses. In: Proc. of the 7th Int. Conf. on Educ. Data Mining. pp. 405-406. , London, UK (2014).

7. Labarthe, H., Bouchet, F., Bachelet, R., Yacef, K.: Does a Peer Recommender Foster Students' Engagement in MOOCs? In: Barnes, T., Chi, M., and Feng, M. (eds.) Proc. of the 9th Int. Conf. on Educational Data Mining. pp. 418-423. Raleigh, NC, USA (2016).

8. Potts, B.A., Khosravi, H., Reidsema, C., Bakharia, A., Belonogoff, M., Fleming, M.: Reciprocal Peer Recommendation for Learning Purposes. In: Proc. of the 8th Int. Conf. on Learning Analytics and Knowledge. pp. 226-235. ACM, New York, NY, USA (2018).

9. Biancani, S., McFarland, D.: Social Networks Research in Higher Education. Educ. Stud. 85-126 (2013).

10. Poquet, O., Dawson, S.: Untangling MOOC Learner Networks. In: Proc. of the 6th Int. Conf. on Learning Analytics \& Knowledge. pp. 208-212. ACM, New York, NY, USA (2016). 